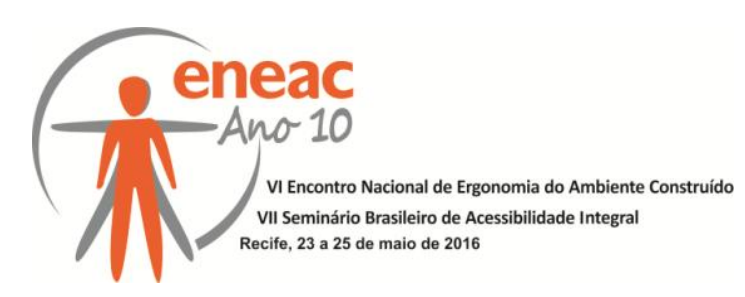

\title{
ANÁLISE DA ACESSIBILIDADE DA PREFEITURA MUNICIPAL DE PATOS-PB
}

\author{
SOUSA, Thays (1); \\ SILVA, Emmanoel (2); \\ ANDRADE, Jerfeson (3); \\ FERNANDES, Júlio (4). \\ (1) Faculdades Integradas de Patos, graduanda em Arquitetura e Urbanismo \\ e-mail:thaysmedeiros74@hotmail.com \\ (2) Faculdades Integradas de Patos, graduando em Arquitetura e Urbanismo \\ e-mail:emmanuel marquess7@hotmail.com \\ (3) Faculdades Integradas de Patos, graduando em Arquitetura e Urbanismo \\ e-mail:jerfeson97@outlook.com \\ (4) Faculdades Integradas de Patos, mestre em Engenharia de Produção (UFRN) \\ e-mail:julio dsi@yahoo.com.br
}

\begin{abstract}
RESUMO
Este artigo analisa a acessibilidade na prefeitura municipal de Patos - PB, localizada na Rua Pedro Firmino - Centro. Com a finalidade de expor os problemas da acessibilidade existentes no local, foram realizadas pesquisas bibliográficas em livros, estudos da norma técnica NBR 9050 (ABNT, 2015), leis e decretos. Foram utilizados métodos interativos e observacionais para a análise do edifício, constatando que a prefeitura encontra-se em desacordo com as normas legais de acessibilidade.
\end{abstract}

Palavras chave: acessibilidade; pessoa com deficiência; mobilidade reduzida; prefeitura municipal.

\begin{abstract}
This article analyzes at accessibility in city hall of Patos - PB, located at Rua Pedro Firmino. In order to explain the problems of accessibility existing at the place. They were carried out bibliographic research in books, studies of technical standard of accessibility NBR 9050 (ABNT, 2015), laws and decrees. Methods were used interactive and observational for the analysis of edifice, noting that the city hall is at odds with legal accessibility standards.
\end{abstract}

Keywords: accessibility; disabled; handicapped; city hall.

\section{INTRODUÇÃO}

No ultimo censo realizado pelo Instituto Brasileiro de Geografia e Estatística (IBGE) no ano de 2010, foi visto que mais de 45,6 milhões de brasileiros tem algum tipo de deficiência, seja ela visual, auditiva, mental ou motora, representando um percentual de $23,9 \%$ da população. Em escala por região, temos o nordeste com o maior número de pessoas com deficiência (PCD), 26,6\% da população e em escala federativa, o Rio Grande do Norte e Ceará em primeiro lugar. Em terceiro lugar, a Paraíba segue com $27,7 \%$ da população com algum tipo 


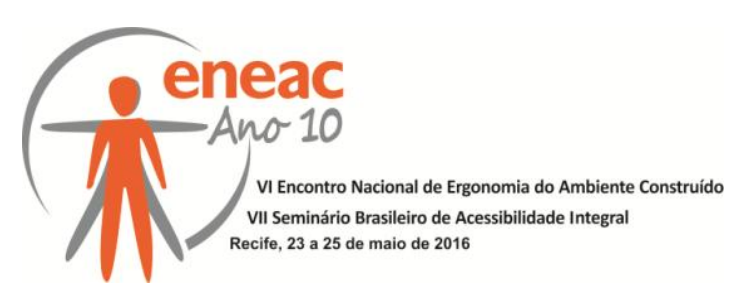

de deficiência, os maiores registros estão nas cidades de João Pessoa - 11.005 PCD, Campina Grande - 5.265 PCD, Santa Rita - 2.290 PCD, Bayeux - 2.131 PCD e Patos - 1.609 PCD (IBGE, 2010).

De acordo com o portal da prefeitura municipal de Patos PB, a edificação foi construída no ano de 1940 desde a sua elaboração até os dias atuais a edificação analisada passou por varias reformas, mediante a isso a prefeitura ainda não se adequou as normas legais de acessibilidade, tomando como solução, medidas paliativas, na construção de uma rota de difícil acesso. De acordo com a NBR 9050 (ABNT, 2015) todo edificação ao passar por reformas deve se enquadrar as normas de acessibilidade existentes.

A disposição interna dos ambientes de edificações históricas normalmente não favorece uma boa orientação espacial, gerando uma necessidade de melhoria em relação à acessibilidade e ao mesmo tempo entrando em confronto com o empenho de conservar suas características arquitetônicas (ANDRADE \& BINS ELY, 2012).

O trabalho tem como meta a mobilização da sociedade perante a inclusão social, com igualdade de oportunidade e exercício da cidadania, aplicada na elaboração de um projeto acessível para a cidade de Patos-PB. Na experiência vivenciada pelos pesquisadores na prefeitura municipal, gerou a reflexão sobre a importância da aplicação das normas legais nas construções de edificações e a necessidade de instruir-se sobre o direito de ir e vir livremente.

\section{ACESSIBILIDADE}

As primeiras discussões sobre o tema acessibilidade foram realizadas nos Estados Unidos com a criação da Lei de Reabilitação, que viabilizava a adaptação em escolas e locais de trabalho. Pós-segunda guerra mundial e o fim da guerra do Vietnã a causa da acessibilidade ganhou mais destaque, pois os vencedores foram acometidos de problemas que reduziram sua mobilidade física, gerando a necessidade de adaptação dos edifícios para sua reinclusão social. Em 1981 a Organização das Nações Unidas (ONU), declarou o mesmo, como ano da acessibilidade, realizando a criação de leis e normas (FROTA, 2010).

No Brasil, em 1994 ocorreu à criação da primeira norma regulamentadora sobre acessibilidade, a NBR 9050 pela Associação Brasileira de Normas Técnicas com o título: "Acessibilidade de pessoas portadoras de deficiências a edificações, espaço mobiliário e equipamentos Urbanos", ocorrendo modificações ao longo dos anos, sendo a primeira realizada no ano de 2004 e a última em 2015, trazendo novos conceitos, argumentos e regras para o melhoramento do desenvolvimento do tema (FROTA, 2010).

De acordo com a NBR 9050 (ABNT, 2015), amparada pela lei Federal 10.098 (BRASIL, 2000), acessibilidade é a possibilidade e condição de alcance, percepção e entendimento para utilização, com segurança e autonomia, de espaços, mobiliários, equipamentos urbanos, edificações, transportes, informação e comunicação, inclusive seus sistemas e tecnologias, bem como outros serviços e instalações abertos ao público, de uso público ou privado de uso coletivo, tanto na zona urbana como na rural, por pessoa com deficiência ou mobilidade reduzida.

\section{METODOLOGIA}

Inicialmente foram realizadas pesquisas e revisões de literatura acerca do assunto acessibilidade em meios públicos, com base em artigos, livros, leis e na norma brasileira NBR 9050 (ABNT, 2015) que nos garantia o direito de questionamento pela falta de acessibilidade no edifício público. Em seguida, foram feitas visitas técnicas na prefeitura, sendo realizada uma simulação de um cadeirante. 


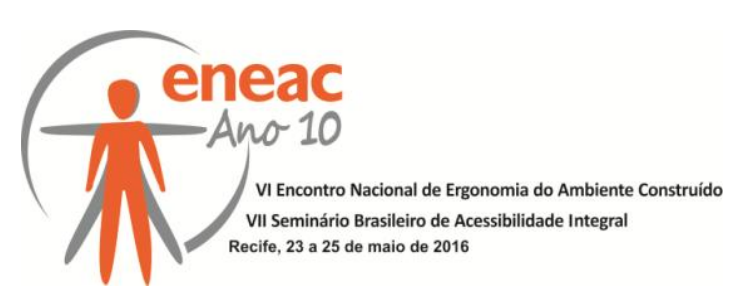

Toda visita teve o auxilio de equipamentos como câmeras fotográficas para realização de registros, que foram utilizados para propagar uma denuncia ao Ministério Público e despertar a visão da sociedade em relação à acessibilidade.

Com uma rota traçada no local, foi realizada uma simulação de um cadeirante por um dos pesquisadores, que por sua vez, constatou a dificuldade que uma pessoa com mobilidade reduzida tem ao acessar o edifício público. Utilizou-se trenas para a medição de guias rebaixadas, portas, rampas, circulação interna e externa, demonstrando que todas as medidas de inclinação, largura e comprimento estão por parte em desacordo com a NBR 9050 (ABNT, 2015). Foi chamada a atenção do público presente para a falta de acessibilidade evidenciada no edifício, gerando uma discursão sobre o tema.

Após toda essa mobilização, houve uma entrevista para a Rádio Espinharas AM da cidade de Patos PB, provocando um debate e questionamentos sobre acessibilidade, envolvendo toda a comunidade e regiões vizinhas. Neste debate realizado pela radio local, a equipe teve como oportunidade defender e expressar a opinião sobre o direito de ir e vir a todos, direito a qual está legitimado pela constituição brasileira (BRASIL, 1988).

\subsection{Rota}

A rota traçada (Figura 1) segue desde a faixa de pedestre até a escada localizada no interior da prefeitura com as respectivas ordens: faixa de pedestre, guia rebaixada, calçada, garagem, rampa de acesso ao interior do edifício, porta e áreas de circulação levando até a escada.

Figura 1 - Rota analisada na Prefeitura Municipal de Patos-PB

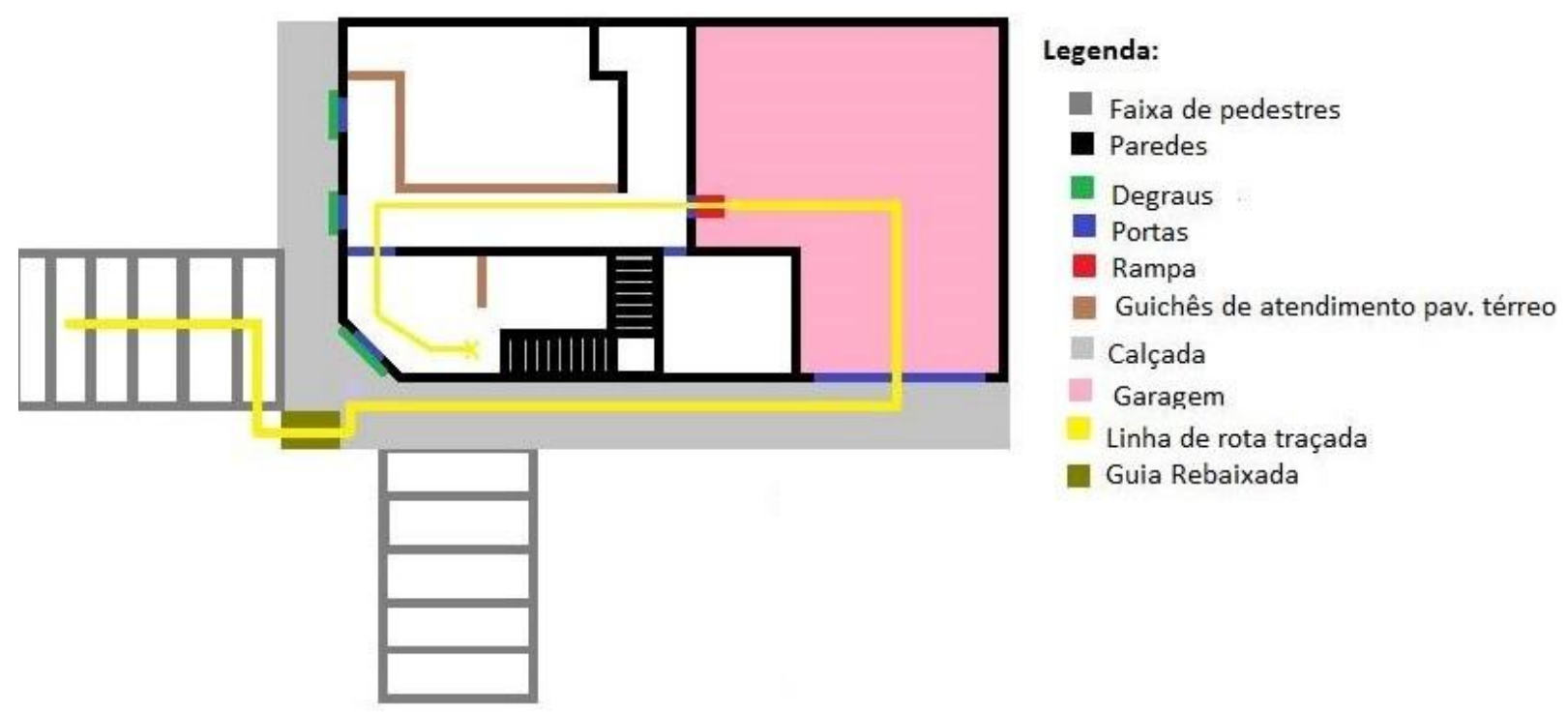

Fonte: Acervo pessoal. 


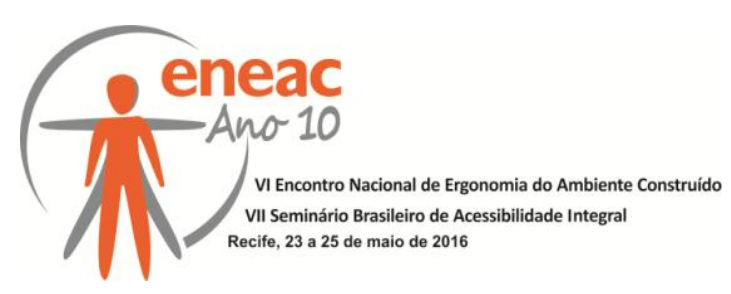

\section{RESULTADOS}

Este capítulo analisa as características da rota traçada pelos pesquisadores e também avalia alguns ambientes da prefeitura que não foram incluídos nessa rota, correlacionando as informações colhidas a leis e normas legais de acessibilidade.

\subsection{Faixa de Pedestre e Guia Rebaixada}

A guia rebaixada que dá acesso à calçada da prefeitura (Figura 2) fica localizada fora da faixa de pedestre, tornando arriscada a circulação das pessoas com deficiência e mobilidade reduzida, devido ao grande fluxo de carros que ali ocorre. O piso da rampa é irregular devido ao uso de publicidade em alto relevo, além disso, sua inclinação é de $12,5 \%$, acima do permitido pela norma e também possui inclinação transversal.

Figura 2 - Lateral da prefeitura e detalhe da guia rebaixada

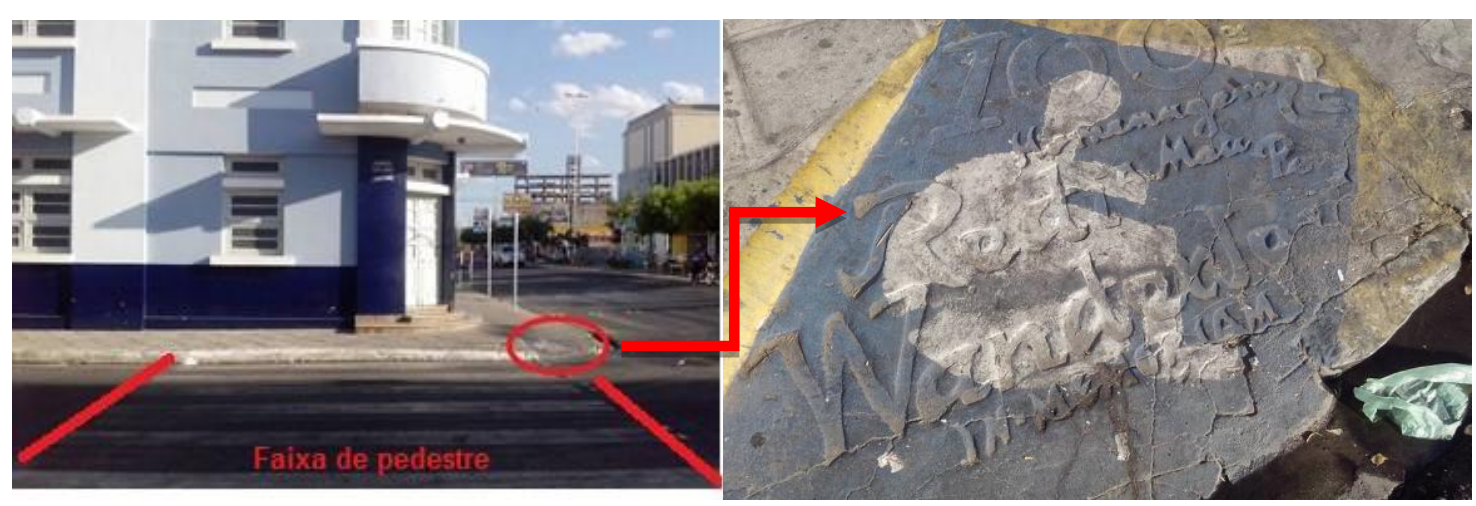

Fonte: Acervo pessoal, 10 de outubro de 2015.

\subsection{Calçada}

A calçada ideal é aquela que garante o caminhar livremente, sendo segura e confortável para todos os cidadãos. Nota-se que a calçada da prefeitura (Figura 3) apresenta largura de 1,80, o que a torna ideal para o passeio conforme a NBR 9050 (ABNT, 2015), contudo, o piso apresenta um leve desnível entre o rejunte e a pedra, causando trepidações em dispositivos com rodas.

Figura 3 - Calçada da prefeitura municipal de Patos

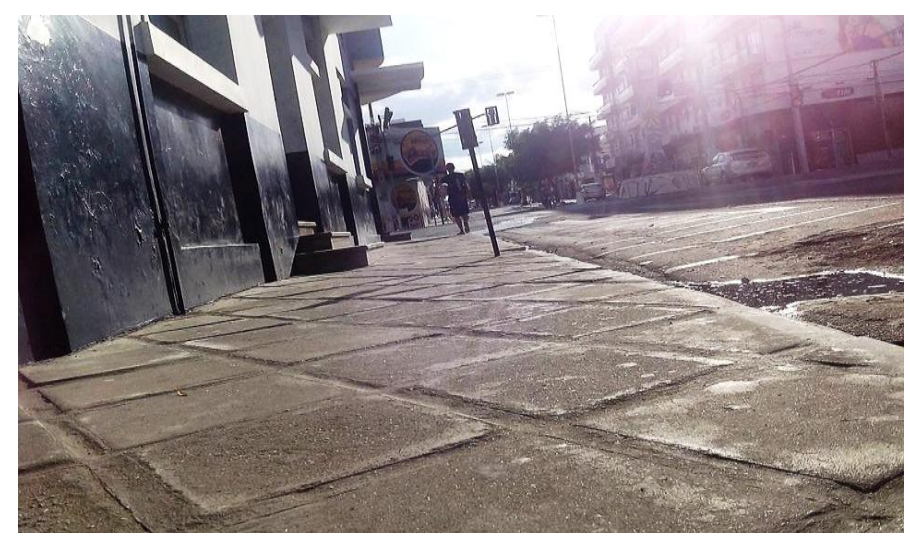

Fonte: Acervo pessoal, 10 de outubro de 2015. 


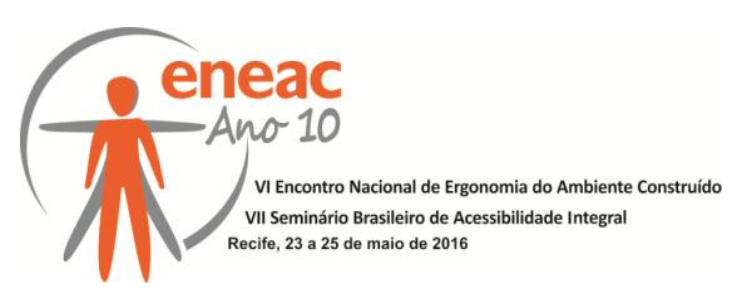

\subsection{Entradas da Prefeitura}

Todas as entradas da prefeitura possuem três degraus (Figura 4), cada degrau possui um espelho de $17 \mathrm{~cm}$, segundo a NBR 9050 (ABNT, 2015) desníveis de qualquer natureza devem ser evitados em rotas acessíveis. Para entrada de pessoas com mobilidade reduzida no edifício, a entrada da garagem seria a única rota disponibilizada pela prefeitura, contudo, o fluxo dessas pessoas pela garagem ainda é arriscado, pois, além de ser um local onde ocorre o transito de automóveis, ainda existe um desnível de $7 \mathrm{~cm}$ entre a calçada da garagem e a calçada das entradas principais , o que dificulta o acesso.

Figura 4 - Entradas da prefeitura de Patos-PB

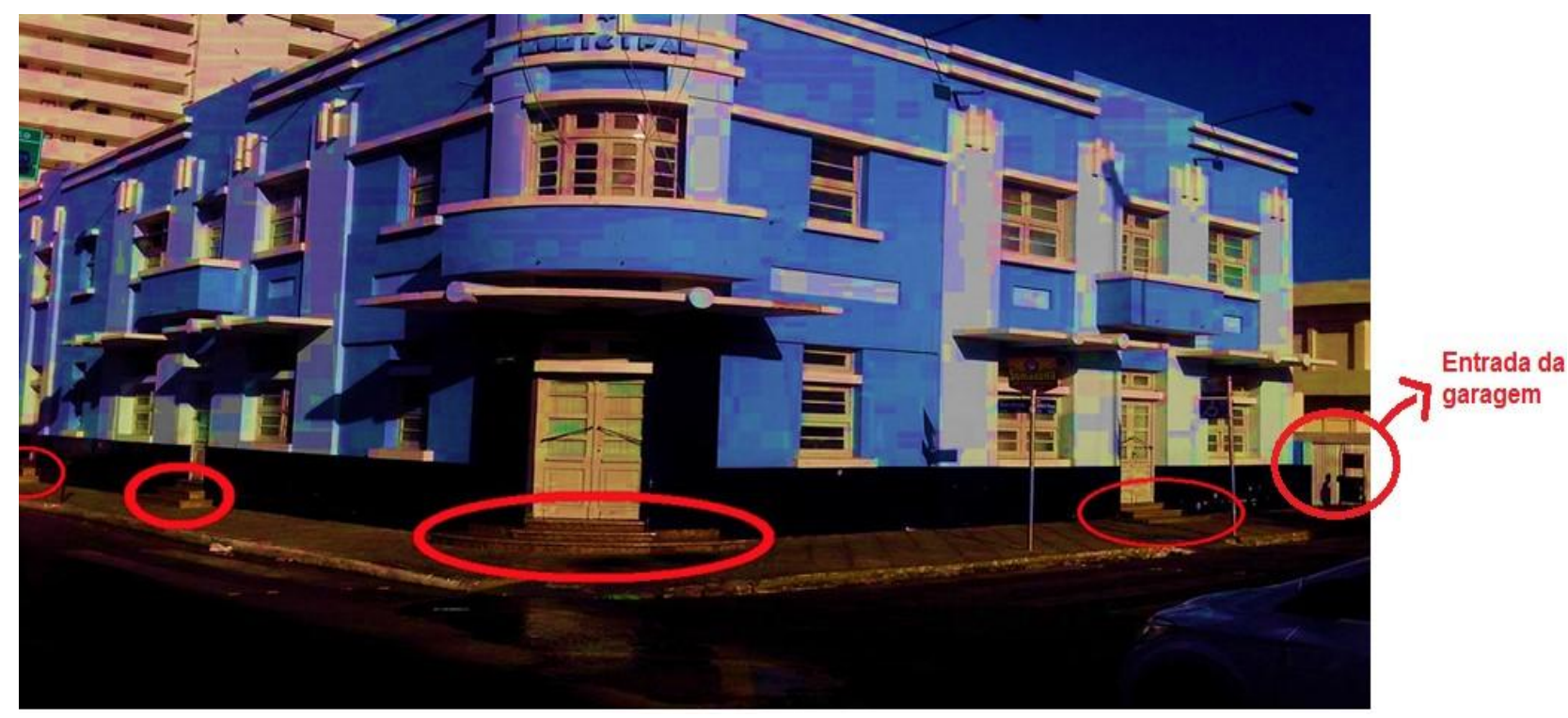

Fonte: Acervo pessoal, 10 de outubro de 2015.

\subsection{Rampa de acesso ao interior}

A falta de rampas nas entradas principais impossibilita que alguém com deficiência ou mobilidade reduzida possa ter acesso ao interior da prefeitura. Para compensar sua entrada irregular, a prefeitura elaborou uma medida paliativa construindo uma rampa com inclinação de $17,14 \%$, sendo acessada pela entrada da garagem, onde ocorre o fluxo de carros. Segundo a NBR 9050 (ABNT, 2015) as rampas devem ter inclinação máxima de 8,33\%. Além disso, a rampa não possui corrimãos, patamares e nenhum tipo de sinalização, o que a torna ainda mais insegura. De acordo com a NBR 9050 (ABNT, 2015), no uso de rampas é necessário a existência de patamares e sinalização. Os patamares devem ter área de, no mínimo, 1,20 m x 1,20 m e a sinalização deve ser feita por meio do símbolo internacional de acesso - SIA.

A porta localizada em frente à rampa possui uma largura de $1 \mathrm{~m}$ e altura de $2,10 \mathrm{~m}$ encontrando-se de acordo com as normas legais da NBR 9050 (ABNT, 2015) que informa que a porta acessível é aquela que possui no mínimo $0,80 \mathrm{~m}$ de largura e 2,10 $\mathrm{m}$ de altura. No entanto, seu posicionamento está inadequado. 


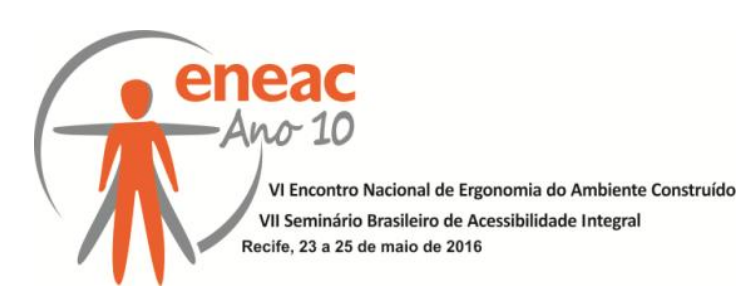

Figura 5 - Rampa de acesso ao interior da Prefeitura

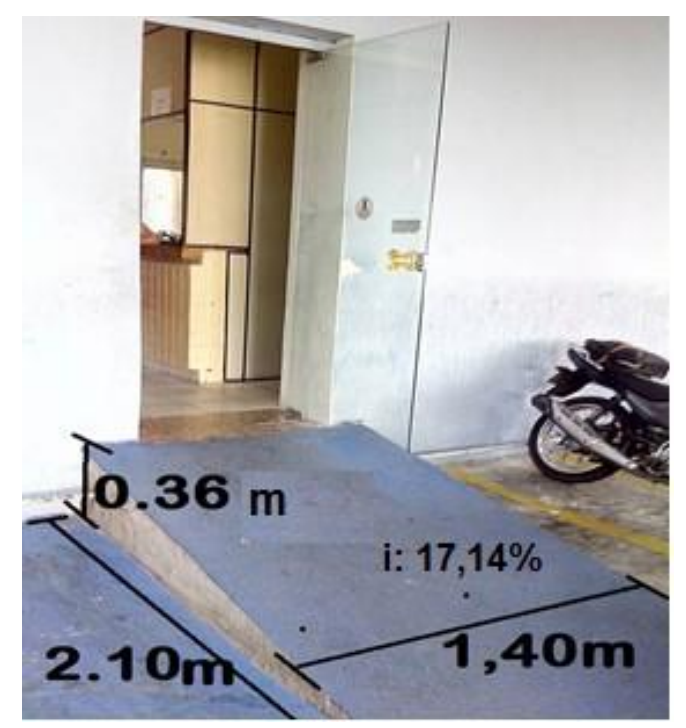

Fonte: Acervo pessoal, 10 de outubro de 2015.

\subsection{Interior da Prefeitura}

No interior da prefeitura há mais uma dificuldade para pessoas com mobilidade reduzida, o único acesso ao pavimento superior é dado por uma escada. As salas disponíveis no pavimento superior do local são: Gabinete da prefeitura, ouvidoria, IPTU, GEO processamento, controle interno, recepção, DAT, fisco e telefonia. Segundo a NBR 9050 (ABNT, 2015), escadas fixas em rotas acessíveis devem estar associadas a rampas ou a equipamentos de transporte vertical.

Os pesquisadores realizaram um questionamento a alguns funcionários da prefeitura "Como uma pessoa com mobilidade reduzida poderia resolver algum problema que fosse direcionado a um serviço exclusivo do pavimento superior, já que não poderia ter acesso àquele local devido às condições impostas?". Como resposta, relataram que caso isso aconteça, o servidor da prefeitura terá que descer e realizar o atendimento no térreo. Embora que, alguns desses serviços funcionem no pavimento do térreo, ainda existe aqueles serviços que são exclusivos ao pavimento superior.

Figura 6 - Escada localizada no interior da prefeitura.

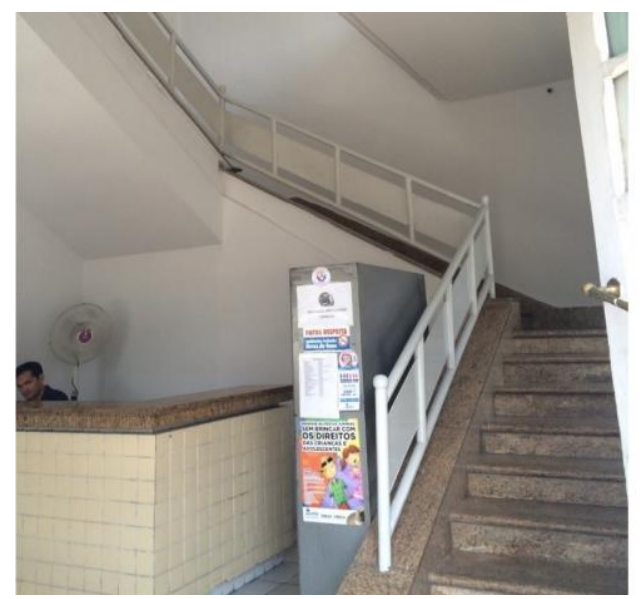

Fonte: Acervo pessoal, 10 de outubro de 2015 


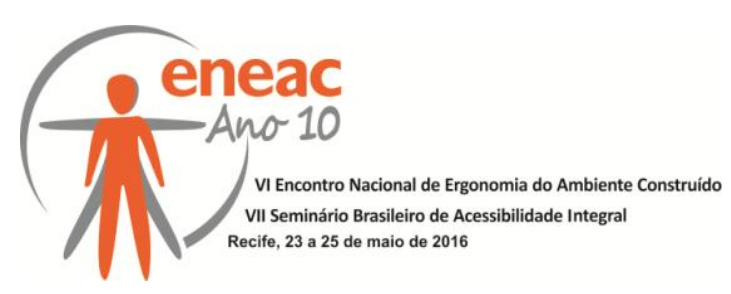

\subsection{Banheiros}

Na rota que dá acesso aos banheiros, foram encontrados outros aspectos em desacordos com a norma de acessibilidade. De acordo com a NBR 9050 (ABNT, 2015), em áreas públicas, a circulação mínima é de 1,20 m, espaço suficiente para circular uma pessoa em cadeira de rodas e uma pessoa em pé. Na prefeitura, o espaço de circulação disponível para esta rota é de apenas $0,90 \mathrm{~m}$.

\section{Figura 7 - corredor localizado no pavimento inferior.}

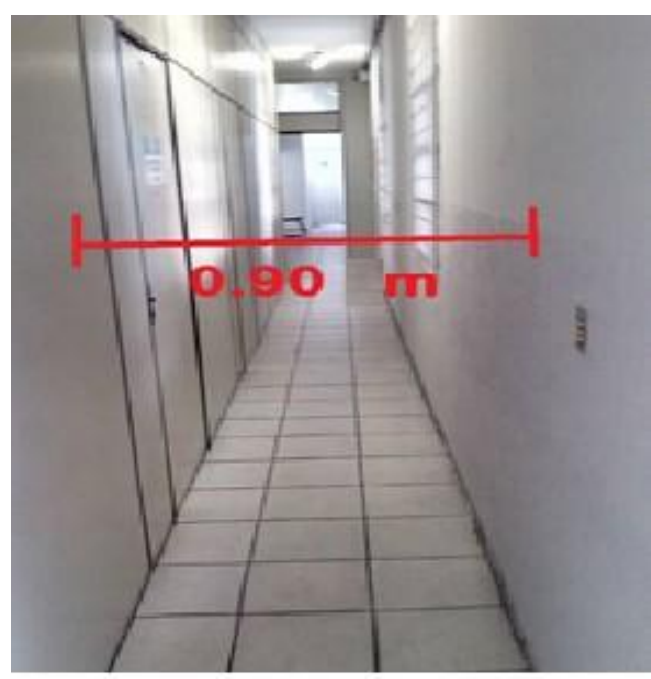

Fonte: acervo pessoal, 10 de outubro de 2015.

As portas dos banheiros possuem apenas $0,60 \mathrm{~m}$ de largura. A NBR 9050 (ABNT, 2015) diz que as portas devem ter um vão livre mínimo de $0,80 \mathrm{~m}$, ou seja, medida referente à parte interna entre os batentes.

Figura 8 - Banheiros masculino e feminino da prefeitura de Patos-PB.

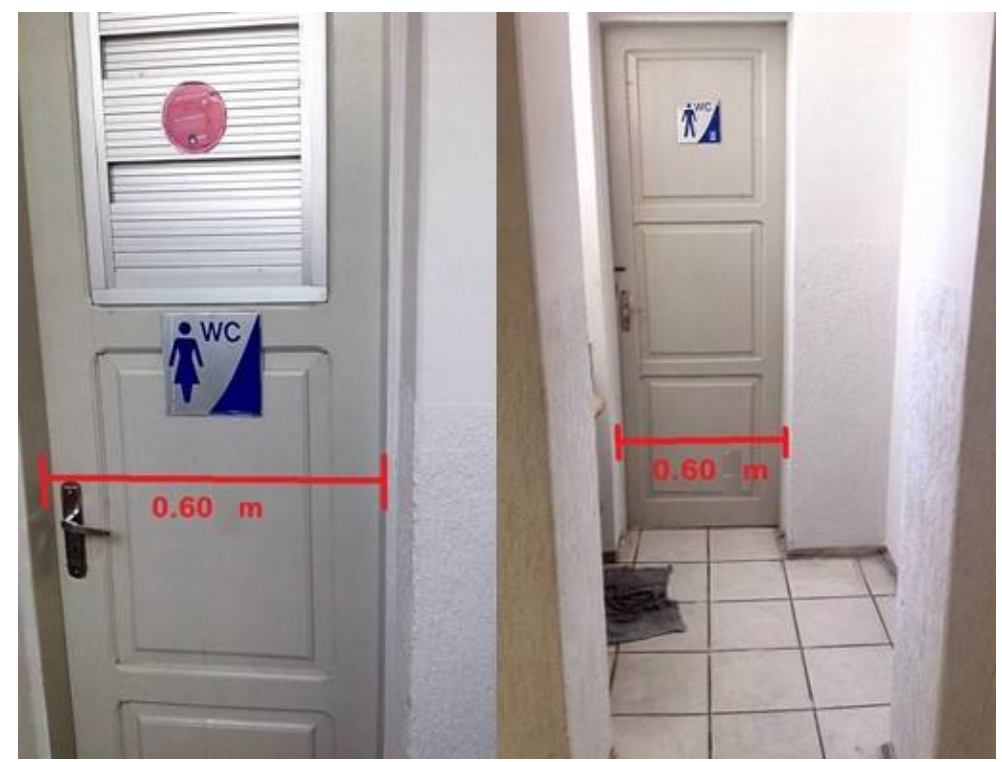

Fonte: acervo pessoal, 10 de outubro de 2015. 


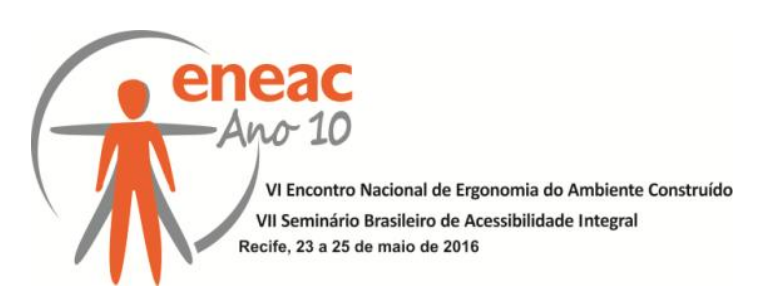

\subsection{Sinalização}

Há falta de sinalização em braile e tátil (de alerta e direcional) em todos os locais da prefeitura, assim como falta sinalização nos degraus isolados e escadas. De acordo com a NBR 9050 (ABNT, 2015) os corrimãos de escadas fixas e rampas devem ter sinalização tátil (caracteres em relevo e em Braille) identificando o pavimento. Essa sinalização deve ser instalada na geratriz superior do prolongamento horizontal do corrimão.

O trajeto deve ser contínuo, desobstruído e sinalizado, que conecte os ambientes externos ou internos de espaços e edificações, e que possa ser utilizado de forma autônoma e segura por todas as pessoas, inclusive aquelas com deficiência e mobilidade reduzida. A rota acessível pode incorporar estacionamentos, calçadas rebaixadas, faixas de travessia de pedestres, pisos, corredores, escadas e rampas, entre outros (ABNT, 2015).

\section{CONCLUSÃO}

Em todo histórico social, a falta de acessibilidade aos recursos, investimento e planejamento político, é considerado um prejuízo para sociedade. Esses prejuízos necessitam ser reparados, para isso, é preciso romper os padrões do assistencialismo e da dependência, incentivando e ampliando recursos a fim de garantir a inclusão de todos e reintegrar as pessoas com deficiência ou algum tipo de restrição, favorecendo a autonomia e construindo um novo conceito de pessoas independentes (POLIA \& GALVÃO, 2014).

Segundo a Constituição brasileira (BRASIL, 1988), todos possuem o direito de ir e vir livremente, mas para que isso aconteça, precisamos de otimização nos projetos e de eficácia na fiscalização pelos órgãos públicos.

Conforme disposto no Decreto ํo 5.296 (BRASIL, 2004), a concepção e a implantação dos projetos arquitetônicos e urbanísticos devem atender aos princípios do desenho universal, tendo como referências básicas as normas técnicas de acessibilidade da ABNT, a legislação específica e as regras contidas neste decreto.

Mediante a Lei Federal 10.098 (BRASIL, 2000) e a NBR 9050 (ABNT, 2015) toda a prefeitura municipal da cidade de Patos PB encontra-se em total desacordo com as mesmas afligindo normas legais e leis federais.

Uma proposta para a melhoria da edificação da prefeitura seria a elaboração de um novo projeto que preservasse a sua identidade e a modificasse apenas em termos de normas legais de acessibilidade. Para isso seria preciso construir rampas, mudar o piso da calçada, instalar um elevador ou uma plataforma elevatória, respeitar as medidas mínimas em todas as portas e locais de circulação, eliminar os desníveis e incorporar uma sinalização adequada em todo ambiente.

Por fim, esta pesquisa possibilitou uma visão ampla do papel do arquiteto na sociedade, em relação a acessibilidade e outras problemáticas, permitindo maior conhecimento sobre leis e normas técnicas. A prática com cadeiras de rodas para o desenvolvimento da análise nos impulsionou a sermos mais humanos e pensarmos mais no próximo, assim questionamos o ambiente em que vivemos, mobilizando todos na busca de melhorias na construção da cidade. 


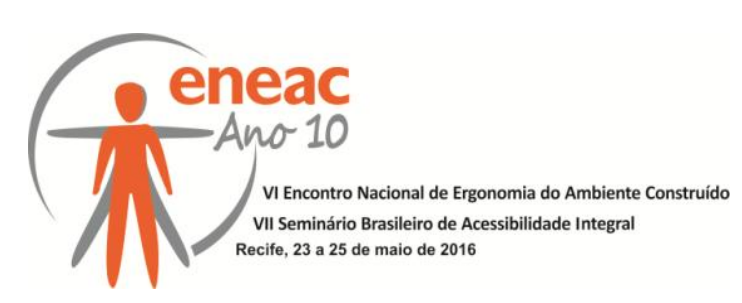

\section{REFERÊNCIAS BIBLIOGRÁFICAS}

ANDRADE, Isabela Fernandes ; BINS-ELY, V. H. M. . Edificações históricas preservadas: intervir para torná-las acessíveis. Ação Ergonômica, v. 7, p. 76, 2012.

ASSOCIAÇÃO BRASILEIRA DE NORMAS TÉCNICAS. NBR 9050 Acessibilidade a edificações, mobiliário, espaços e equipamentos urbanos. 3 ed Rio de Janeiro, Rj: ABNT, 2015.

BRASIL. Constituição (1988). Constituição da República Federativa do Brasil. Brasília. Disponível em: <http://www.planalto.gov.br/ccivil 03/Constituicao/Constituicao.htm>. Acesso em: 18 jan. 2016.

BRASIL. Constituição (2000). Lei no 10.098, de 19 de dezembro de 2000. Critérios Básicos Para A Promoção da Acessibilidade das Pessoas Portadoras de Deficiência Ou Com Mobilidade Reduzida.

BRASIL. Constituição (2004). DECRETO № 5.296 DE dois DE DEZEMBRO DE 2004. DO ATENDIMENTO PRIORITÁRIO.

FROTA, Thais. Quando e onde começaram a falar em Acessibilidade?. 2010. Disponível em: <http://www.vidamaislivre.com.br/colunas/post.php?id=479\&/quando e onde comecaram a falar e $\underline{\mathrm{m} \text { acessibilidade }}>$. Acesso em: $29 \mathrm{dez} .2015$.

IBGE. CENSO Demográfico 2010. Disponível em: http://www.ibge.gov.br. Acesso em: 20/01/2016.

POLIA, Andreza Aparecida; GALVÃO, Cláudia Regina Cabral. Acessibilidade no ambiente construído: $O$ papel da terapia ocupacional e a aplicação da tecnologia assistiva. In: COSTA, Angelina Dias Leão; ARAÚJO, Nelma Mirian Chagas. 2ª edição. João Pessoa: IFPB, 2014.

PATOS-PB. Prefeitura Municipal (Org.). Sobre Patos. Disponível em: <http://www.patos.pb.gov.br/governo e municipio/cidade>. Acesso em: 18 jan. 2016. 